\title{
ARBORIZAÇÃO URBANA NA CIDADE DE PAULISTANA-PI: UMA ANÁLISE DAS PRAÇAS PÚBLICAS
}

\author{
URBAN AFFORESTATION IN PAULISTANA -PI: AN ANALYSIS OF \\ THE PUBLIC SQUARES
}

\author{
ljan de Carvalho Silva ${ }^{1}$, Vanessa Teresinha Ribeiro²
}

\section{RESUMO}

O município de Paulistana possui uma área de 1.969,955 km², sua zona urbana divide-se em 18 (dezoito) bairros, sendo que destes apenas 4 (quatro) possuem praças. O presente trabalho teve como objetivo a realização de uma análise das 4 (quatro) praças públicas existentes no município de Paulistana-PI para se obter um diagnóstico da arborização das mesmas. A metodologia aplicada caracteriza-se como um estudo de campo, consistindo em um levantamento das condições físicas das praças, identificação das espécies arbóreas, ocorrência, bem como o estado físico de cada indivíduo arbóreo, porte e poda. Foram analisados a frequência em que cada indivíduo aparece e o Índice de Densidade Arbórea (IDA) para cada praça. Na pesquisa realizada, foram identificados 76 indivíduos distribuídos em 11 espécies. Das quatro praças estudadas, três apresentavam IDA para cada $100 \mathrm{~m}^{2}$ de área abaixo de 1 , denotando carência de vegetação arbórea. Os resultados obtidos mostram que a situação arbórea do município em estudo apresenta problemas, principalmente na seleção e distribuição das espécies, além da manutenção das mesmas. Este fato evidencia a necessidade da implantação de políticas públicas voltadas à arborização dos espaços urbanos da cidade, a fim de ampliar a biodiversidade e o bem estar da população local.

Palavras-chave: Espécies arbóreas; Biodiversidade; Espaços urbanos.

\section{ABSTRACT}

The municipality of Paulistana has an area of $1,969,955 \mathrm{~km}^{2}$, its urban zone is divided into 18 (eighteen) neighborhoods, of which only 4 (four) have squares. The following study aimed to conduct a survey in the 4 (four) existing public squares in Paulistana-PI to obtain a diagnosis of their afforestation. The methodology is characterized as a field study which consists of a research on the physical conditions of the square, identification of tree species, occurrence, as well as the physical condition of each individual tree, size and pruning. It was analyzed the frequency of each individual tree, and the Arboreal Density Index (ADI) for each square. In the survey, it was identified 76 individuals in 11 species. In relation to the four studied regions, three presented $A D I$ for each area of $100 \mathrm{~m}^{2}$ below 1 , denoting lack of tree vegetation. The results show that the arboreal situation of the city presents problems, especially in the selection and distribution of the species, as well as in their maintenance. This fact evidence the need to implement public policies for the afforestation of urban spaces of the city, in order to expand biodiversity and the welfare of the local population.

Keywords: Arboreal species; Biodiversity; Urban spaces.

Recebido em 23.09.2016 e aceito em 16.02.2017

1 Licenciado em Computação, Especialista em Gestão e Educação Ambiental, Técnico Administrativo em Educação do Instituto Federal do Piauí. Paulistana/PI. E-mail: ijancs@gmail.com

2 Licenciada em Química, Especialista em Gestão e Educação Ambiental, Técnica Administrativo em Educação do Instituto Federal do Piauí, Paulistana/PI. E-mail: vanessairineu@hotmail.com 


\section{INTRODUÇÃO}

O crescimento demográfico em espaços urbanos, tem sido uma grande preocupação dos estudiosos e planejadores urbanos. Conforme Rezende e Santos (2010), esse crescimento traz em si inúmeros problemas, tendo em vista que o ambiente urbano é intensamente alterado pelas edificações e loteamentos do solo que restringem os espaços determinados às áreas verdes.

Políticas públicas devem ser voltadas para a conservação desses ambientes ou ao menos a substituição por ambientes o mais próximo possível da realidade local, com o objetivo de aproximar o homem da natureza e manter o equilíbrio ecológico (OLIVEIRA et al., 2013).

A preservação de áreas verdes em espaços urbanos constitui um importante instrumento para manter esse equilíbrio, contribuindo principalmente na prevenção da ocorrência de pragas que podem se proliferar por algum desequilíbrio ambiental provocado pela ação do homem. Assim posto, Rezende e Santos (2010), ainda, afirmam que os benefícios proporcionados pela arborização são diversos, principalmente de cunho ecológico, estético, econômico e social.

Segundo Oliveira et al. (2013), a arborização urbana pode ser considerada como um dos mais importantes elementos naturais que compõem o ecossistema das cidades e que, pelos benefícios que produz, deveria compor de maneira sistematizada qualquer planejamento urbano.

Para alcançar a qualidade do ambiente urbano é necessário realizar um planejamento prévio, para que não surjam problemas decorrentes do plantio, levando em consideração que a arborização deve ser a mais diversificada possível, por motivos estéticos, pela preservação da fauna e da própria biodiversidade vegetal e da cultura regional (FERREIRA; AMADOR, 2013, p. $63)$.

É importante ressaltar que as praças públicas constituem um referencial urbano, marcado pela convivência humana, devendo ser preservadas e arborizadas de forma que se garanta a manutenção e qualidade de vida das espécies.

O planejamento da arborização não é uma tarefa simples e deve levar em conta vários elementos, já que não se trata de um fator isolado, e sim de um contexto. [...] deve-se levar em consideração no momento da implantação da vegetação características como clima, solos, topografia, espaço físico disponível, as características das espécies, especialmente quanto à tolerância à poluição, ausência de princípios tóxicos e/ou alérgicos, entre outras características inerentes a morfologia e fenologia da espécie (EMER et al., 2011, p. 2).

A cidade de Paulistana-PI, localizada na microrregião do alto médio Canindé, sudeste piauiense, situa-se no bioma caatinga, se caracteriza por apresentar altas temperaturas e baixa umidade do ar entre os meses de setembro a novembro (IBGE, 2015). Fundado em 1939, o 
município teve seu crescimento de forma não planejada, causando diversos problemas ambientais, dentre eles a diminuição das paisagens naturais.

Nesse contexto, tem-se o levantamento de dados da arborização de praças como fundamental para que se tenha o devido conhecimento sobre a qualidade das mesmas, identificando sua função biológica para a população e seu manejo mais adequado.

Esse monitoramento é indispensável para a adequação do crescimento das cidades, evitando problemas futuros. Assim, o presente estudo visou realizar uma análise das praças públicas existentes no município de Paulistana-PI para se obter um diagnóstico da arborização das mesmas.

\section{MATERIAL E MÉTODOS}

O presente estudo foi desenvolvido no município de Paulistana, região sudeste do estado do Piauí. Compreende uma área de 1.969,955 km², uma densidade demográfica de $10,04 \mathrm{hab} / \mathrm{km}^{2}$ e tem como limites o município de Jacobina - PI ao norte, Queimada Nova- PI ao sul, Betânia-PI e Acauã-PI ao leste e São Francisco de Assis do Piauí-PI ao oeste. Paulistana localiza-se a $08^{\circ} 08^{\prime} 37^{\prime \prime} \mathrm{S}$ e $41^{\circ} 08^{\prime} 59^{\prime \prime} \mathrm{W}$, apresenta uma altitude média de 359 metros e distância 459,5 km da capital do estado Teresina (IBGE, 2010).

Apresenta clima Tropical semiárido quente, com duração do período seco de sete a oito meses. A vegetação é a Caatinga arbórea e arbustiva e solo Latossolos vermelho-amarelo associados a solos litólicos e podzólicos vermelho-amarelo eutróficos (CEPRO, 2013).

Na pesquisa foram analisadas todas praças públicas existentes na sede do município, a saber: Praça Capitão Valério Coelho, localizada no centro da cidade; Praça Ana Maria de Jesus, localizada no bairro Guarita; Praça de Alimentação Salvador José Rodrigues, localizada às margens da BR 407; e Praça Adão José dos Santos, localizada no bairro Correnteza.

O presente estudo se caracteriza como uma pesquisa de campo e divide-se em três etapas: pré-campo, campo e pós-campo. Na etapa de pré-campo realizou-se a pesquisa bibliográfica, para o delineamento dos mecanismos de trabalho e confecção de uma planilha para coleta de dados em campo. A planilha apresenta campos para preenchimento com informações gerais (data da coleta, nome da praça, localização, coordenadas geográficas e estrutura física) e informações sobre arborização (espécie, origem, estado, poda e porte).

$\mathrm{Na}$ etapa de campo, realizou-se a visita in loco para a analise quali-quantitativa das praças, a partir do levantamento sobre a caracterização arbórea, bem como informações sobre o estado físico das mesmas. 
$\mathrm{Na}$ etapa posterior, pós-campo, os dados coletados e registrados na planilha foram consolidados e discutidos, sendo feita a análise de dados em características de valores numéricos da densidade de indivíduos arbóreos, frequência, características e condições em que esses indivíduos se apresentavam.

O Índice de Densidade Arbórea (IDA) por praça foi calculada pela razão entre o número de indivíduos arbóreos presentes e a área aproximada de cada praça, sendo esta calculada utilizando as coordenadas geográficas de suas extremidades, realizando tal operação com o auxílio do software Google Earth (LIMA NETO; SOUSA, 2009). A frequência de cada espécie foi determinada por meio da razão entre o número de indivíduos da espécie e o número total de indivíduos da praça.

Quanto ao estado e as características dos indivíduos arbóreos foi adotado como critério o método observacional, realizado in loco. Foram considerados os seguintes níveis: para o estado - bom (não apresenta sinais de pragas doenças ou injurias mecânicas), satisfatório (apresenta sinais de pragas doenças ou danos físicos, necessitando de poda corretiva, reparo de danos físicos ou controle sanitário), ruim (severos danos de pragas, doenças ou defeitos físicos e, não aparentando morte iminente) ou morto (apresenta danos irreversíveis de pragas, doenças ou graves danos físicos); para a poda - drástica (copa rebaixada agressivamente, sem qualquer critério técnico podendo ocasionar morte), boa (obedece os critérios técnicos, essencial para o desenvolvimento e manutenção) e sem poda; e para o porte: muda ( $<=1 \mathrm{~m}$ ), pequeno (entre 1,01 e $3 \mathrm{~m}$ ), médio (entre 3,01 e $6 \mathrm{~m}$ ) ou grande (acima de $6 \mathrm{~m}$ ).

\section{RESULTADOS E DISCUSSÃO}

Durante a pesquisa foram encontrados um montante de 76 (setenta e seis) indivíduos arbóreos distribuídos em 11 (onze) espécies. Destas, apenas 3 espécies são nativas do Brasil, o que corresponde a aproximadamente $27 \%$. As $73 \%$ restantes (8 espécies) são consideradas exóticas, conforme apresentado na Tabela 1.

O somatório da FA de indivíduos exóticos encontrados é de 63 (sessenta e três), o que representa uma FR de $85,71 \%$ dos indivíduos.

As árvores nativas registradas foram: Peltophorum dubium, sendo encontrados 9 (nove) indivíduos em 3 (três) das 4 (quatro) praças analisadas, distribuídos em 1 (um) indivíduo na Praça Adão José dos Santos, 3 (três) indivíduos na Praça de Alimentação Salvador José Rodrigues e 5 (cinco) indivíduos na Praça Capitão Valério Coelho); Cochlospermum regium, 3 
(três) indivíduos presentes na Praça Adão José dos Santos; e Acrocomia aculeata, 1 (um) indivíduo na Praça Adão José dos Santos, conforme Tabela 2.

Tabela 1. Indivíduos arbóreos identificados segundo nome popular e científico, ocorrência (exótica ou nativa) e valores de frequência absoluta ( $F A)$ e frequência relativa (FR) das praças do município de Paulistana - PI, 2015

Table 1. Identified arboreal individuals according to popular and scientific names, occurrence (exotic or native) and absolute frequency values (AF) and relative frequency (RF) from squares afforestation in Paulistana - PI, 2015

\begin{tabular}{lllccc}
\hline $\mathbf{N}^{\circ}$ & Nome Científico & $\begin{array}{l}\text { Nome } \\
\text { Comum }\end{array}$ & Ocorrência & FA & FR \% \\
\hline 01 & Azadirachta indica (A. Juss.) & Nim & Exótica & 26 & 34,21 \\
02 & Prosopis juliflora (Sw) DC & Algaroba & Exótica & 14 & 18,42 \\
03 & Ficus carica L. & Figueira & Exótica & 13 & 17,10 \\
04 & Peltophorum dubium (Spreng.) Taub & Canafístula & Nativa & 9 & 11,84 \\
05 & Mangifera indica (Linnaeus) & Mangueira & Exótica & 4 & 5,26 \\
06 & Cochlospermum regium (Mart. ex & Algodão & Nativa & 3 & 3,94 \\
& Schrank) Pilg. & Bravo & & & \\
07 & Pithecellobium Dulce (Roxb.) Benth & Mata Fome & Exótica & 2 & 2,63 \\
09 & Erythrina variegata (L.) Merr & Brasileirinho & Exótica & 2 & 2,63 \\
09 & Delonix regia (Hook.) Raf. & Flamboyant & Exótica & 1 & 1,31 \\
10 & Licania tomentosa (Benth.) Fritsch & Oiti & Exótica & 1 & 1,31 \\
11 & Acrocomia aculeata (Jacq.) Lodd ex Mart. & Macaúba & Nativa & 1 & 1,31 \\
\hline \hline
\end{tabular}

Tabela 2. Praças estudadas com nome e número de indivíduos arbóreos e o número de espécies encontradas no município de Paulistana - PI, 2015

Table 2. Studied Squares with name and number of arboreal individuals and the number of species found in Paulistana - PI, 2015

\begin{tabular}{|c|c|c|c|c|}
\hline $\begin{array}{l}\text { Nome da } \\
\text { Praça }\end{array}$ & $\begin{array}{c}\text { Área } \\
\text { aproximada } \\
\left(\mathrm{m}^{2}\right)\end{array}$ & Espécie & FA & TOTAIS \\
\hline \multirow{8}{*}{$\begin{array}{l}\text { Adão José } \\
\text { dos Santos }\end{array}$} & \multirow{8}{*}{800} & Azadirachta indica & 4 & \multirow{5}{*}{15 Indivíduos } \\
\hline & & Cochlospermum regium & 3 & \\
\hline & & Pithecellobium dulce & 2 & \\
\hline & & Erythrina variegata & 2 & \\
\hline & & Peltophorum dubium & 1 & \\
\hline & & Delonix regia & 1 & 8 Espécies \\
\hline & & Mangifera indica & 1 & \\
\hline & & Acrocomia aculeata & 1 & \\
\hline \multirow{3}{*}{$\begin{array}{l}\text { Salvador José } \\
\text { Rodrigues }\end{array}$} & \multirow[b]{3}{*}{4800} & Azadirachta indica & 17 & \multirow{2}{*}{36 Indivíduos } \\
\hline & & Peltophorum dubium & 3 & \\
\hline & & $\begin{array}{l}\text { Ficus carica } \\
\text { Manaifera indica }\end{array}$ & $\begin{array}{r}13 \\
3\end{array}$ & 4 Espécies \\
\hline $\begin{array}{l}\text { Ana Maria de } \\
\text { Jesus }\end{array}$ & 700 & Azadirachta indica & 4 & $\begin{array}{l}4 \text { Indivíduos } \\
1 \text { Espécies }\end{array}$ \\
\hline \multirow{4}{*}{$\begin{array}{l}\text { Capitão } \\
\text { Valério } \\
\text { Coelho }\end{array}$} & \multirow{4}{*}{3200} & Prosopis juliflora & 14 & \multirow{2}{*}{21 Indivíduos } \\
\hline & & Peltophorum dubium & 5 & \\
\hline & & Licania tomentosa & 1 & 4 Fsnécies \\
\hline & & Azadirachta indica & 1 & 4 Especles \\
\hline Total & 9500 & & $\overline{911}$ & \\
\hline
\end{tabular}


Tomando-se como base a análise individual de cada praça, tem-se a Praça Adão José dos Santos como a que apresentou o maior número de espécies (73\%), e a maior variedade de espécies nativas (5 indivíduos dentre 3 espécies).

A mesma mostrou um IDA de 1,87 indivíduo/100m², índice considerado bom, já que, segundo Lima Neto e Souza (2009), o valor mínimo tolerado é de 1 indivíduo para cada $100 \mathrm{~m}^{2}$ (Figura 1). Já em relação ao estado físico da praça, a mesma se caracterizou-se como ruim, apresentando problemas estruturais como: passeios esburacados, canteiros e meios-fios quebrados.

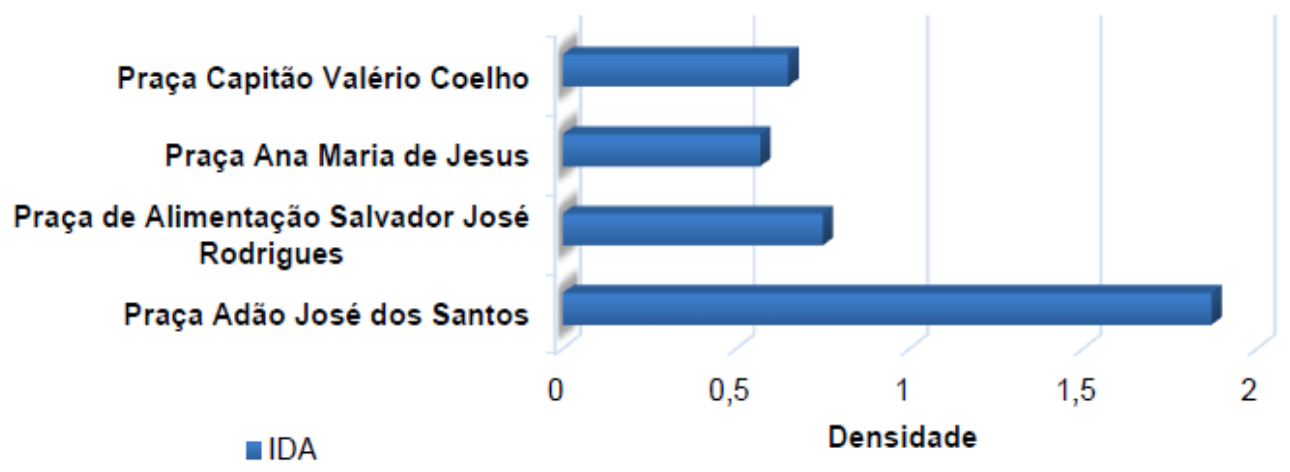

Figura 1. Índice de Densidade Arbórea - IDA das praças de Paulistana - PI, 2015

Figure 1. Arboreal Density Index - ADI of squares in Paulistana - PI, 2015

Com relação ao estado e características dos indivíduos arbóreos, no que se refere à poda e ao porte, foram obtidos os seguintes resultados: dos 15 (quinze) indivíduos registrados na Praça Adão José dos Santos, 8 (oito) se encontravam em bom estado e 7 (sete) em estado satisfatório, 1 (um) indivíduo com poda drástica, 6 (seis) com poda boa e 8 (oito) sem poda (Figuras 2 e 3). Quanto ao porte, 5 (cinco) indivíduos eram mudas, 8 (oito) eram de médio porte e 2 (dois) eram de grande porte, conforme apresentado na Figura 4.

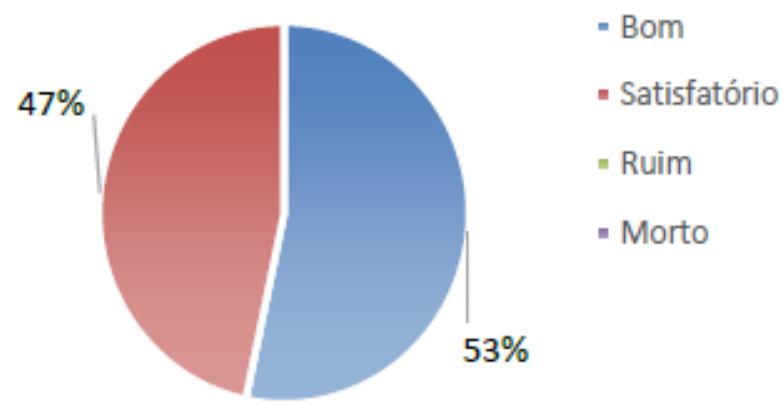

Figura 2. Estado fitossanitário dos indivíduos encontrados na Praça Adão José dos Santos, 2015 Figure 2. Phytosanitary condition of individuals found in Adão José dos Santos Square, 2015 


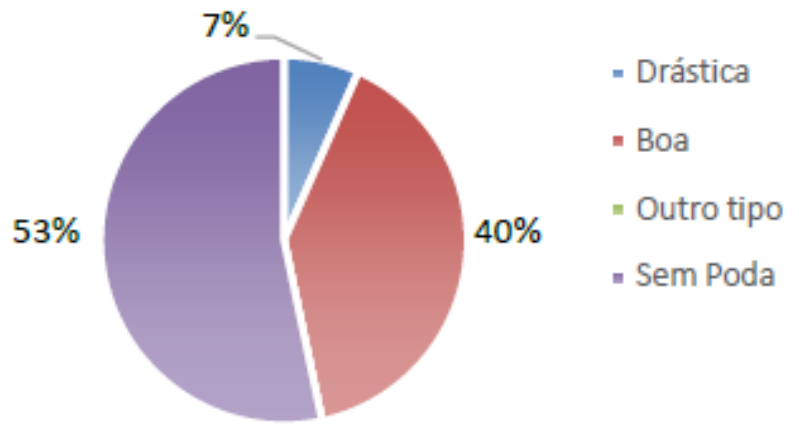

Figura 3. Situação de poda dos indivíduos encontrados na Praça Adão José dos Santos, 2015 Figure 3. Pruning situation of individuals found in Adão José dos Santos Square, 2015

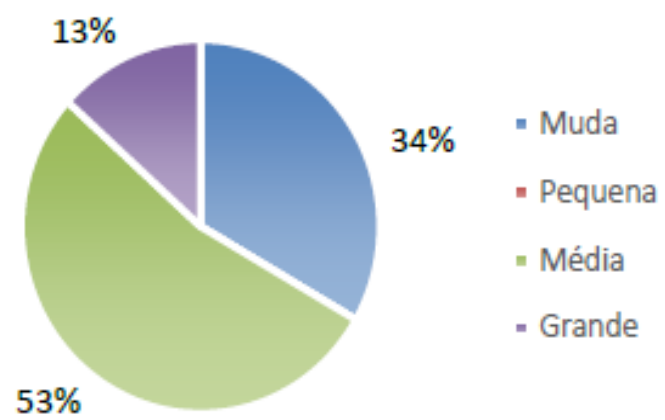

Figura 4. Porte dos indivíduos encontrados na Praça Adão José dos Santos, 2015

Figure 4. Size of the individuals found in Adão José dos Santos Square, 2015

A Praça de Alimentação Salvador José Rodrigues foi a que apresentou um maior número de indivíduos arbóreos (36 indivíduos), 47,36\% do total de indivíduos encontrados nas quatro praças juntas. Porém, o IDA é de 0,75 indivíduo/100m² (Figura 1), considerado baixo.

Esta praça apresentou uma estrutura ótima em um de seus lados, porém no outro se encontrava em estado ruim, apresentando sérios problemas como: meios-fios, passeios, canteiros e bancos quebrados ou danificados e iluminação deficiente.

Quanto ao estado e características dos indivíduos arbóreos, foram obtidos os seguintes resultados diante dos 36 (trinta e seis) indivíduos encontrados: 15 (quinze) indivíduos se encontravam em bom estado, 17 (dezessete) em estado satisfatório, 2 (dois) em estado ruim e 2 (dois) mortos (Figuras 5 e 6). Quanto à poda, 4 (quatro) eram drásticas, 22 (vinte e duas) boas e 10 (dez) sem poda. Quanto ao porte, 4 (quatro) eram mudas e 32 (trinta e dois) de tamanho médio, conforme dados apresentados nas Figura 7. 


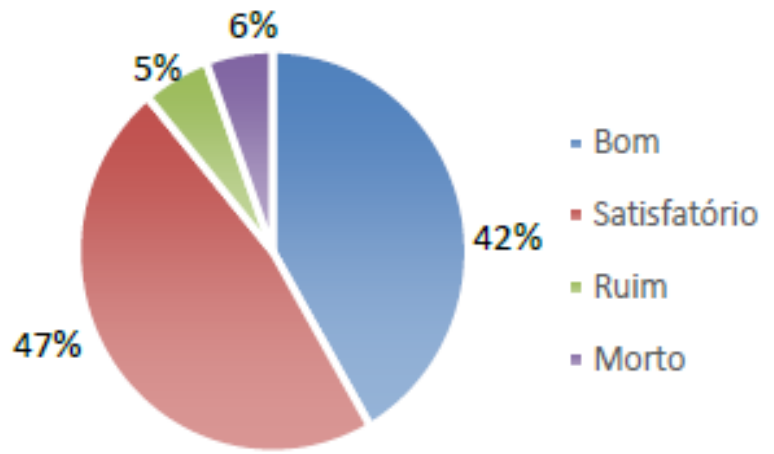

Figura 5. Estado fitossanitário dos indivíduos encontrados na Praça de Alimentação Salvador José Rodrigues, 2015

Figure 5. Phytosanitary condition of individuals found in Salvador José Rodrigues Food Court, 2015

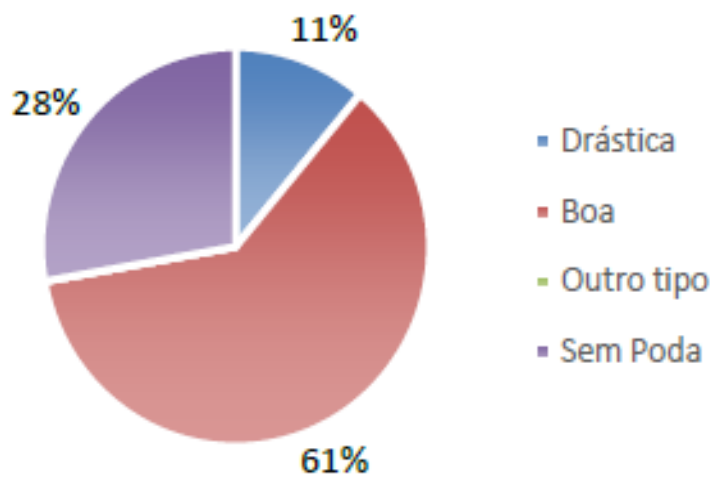

Figura 6. Situação de poda dos indivíduos encontrados na Praça de Alimentação Salvador José Rodrigues, 2015

Figure 6. Pruning situation of individuals found in Salvador José Rodrigues Food Court, 2015

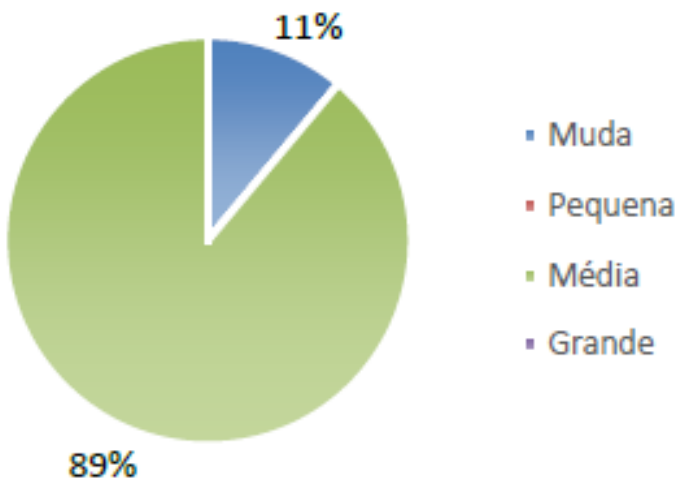

Figura 7. Porte dos indivíduos encontrados na Praça de Alimentação Salvador José Rodrigues, 2015 Figure 7. Size of the individuals found in Salvador José Rodrigues Food Court, 2015

A Praça Ana Maria de Jesus foi a que apresentou o menor número de espécies (1 espécie) e menor IDA (0,57 indivíduos/100m²) (Figura 1), porém mostrou-se seu estado físico o melhor entre as quatro praças estudadas.

$\mathrm{Na}$ referida praça foram encontrados 4 (quatro) indivíduos arbóreos, sendo que todos se apresentavam em bom estado (Figura 8). Quanto à poda 2 (dois) estavam boas e 2 (dois) sem poda (Figura 9). Em relação ao porte, os 4 indivíduos são de porte médio (Figura 10). 


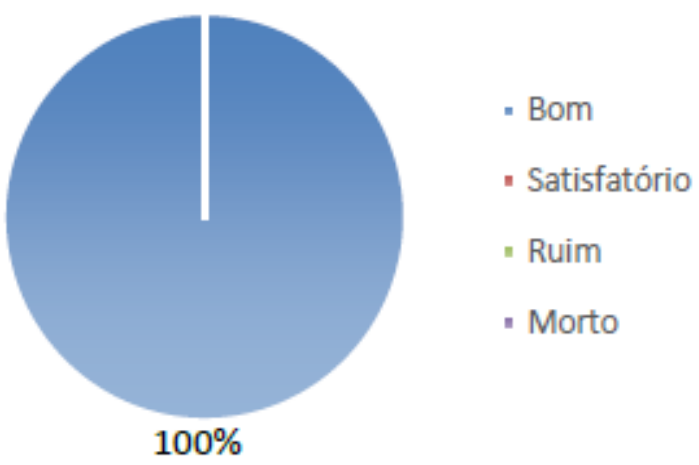

Figura 8. Estado fitossanitário dos indivíduos encontrados na Praça Ana Maria de Jesus, 2015 Figure 8. Phytosanitary condition of individuals found in Ana Maria de Jesus Square, 2015

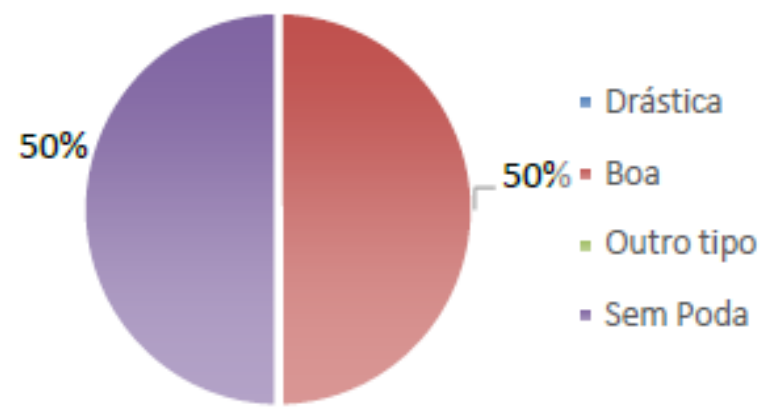

Figura 9. Situação de poda dos indivíduos encontrados na Praça Ana Maria de Jesus, 2015

Figure 9. Pruning situation of individuals found in Ana Maria de Jesus Square, 2015

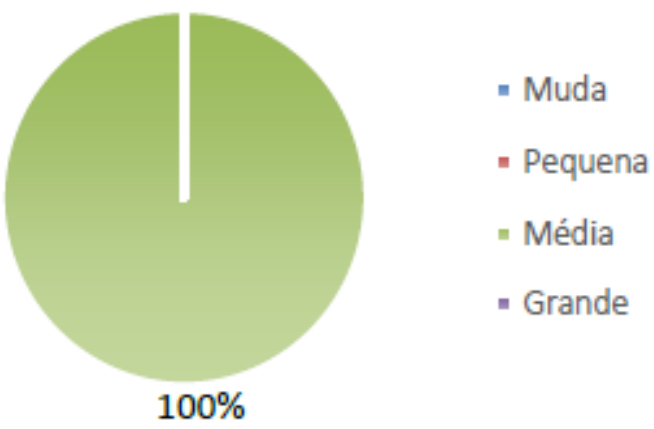

Figura 10. Porte dos indivíduos encontrados na Praça Ana Maria de Jesus, 2015

Figure10. Size of the individuals found in Ana Maria de Jesus Square, 2015

A Praça Capitão Valério Coelho é a mais antiga da cidade, durante o estudo pôde-se observar a presença de problemas tanto em sua estrutura física como em sua composição arbórea. Seu IDA, foi de apenas 0,65 indivíduos/ 100m² (Figura 1). 
Em sua estrutura física observou-se danos nos meios-fios, passeios e canteiros. Quanto ao estado dos indivíduos arbóreos, apenas 1 (um) estava em bom estado, 5 (cinco) em estado satisfatório, 12 (doze) em estado ruim e 3 (três) estavam mortos (Figura 11). Quanto à poda, 1 (um) indivíduo apresentou poda drástica, 15 (quinze) poda boa e 5 (cinco) estavam sem podas (Figura 12). Quanto ao porte, foram encontradas 1 (um) muda e 20 (vinte) indivíduos de porte médio (Figura 13).

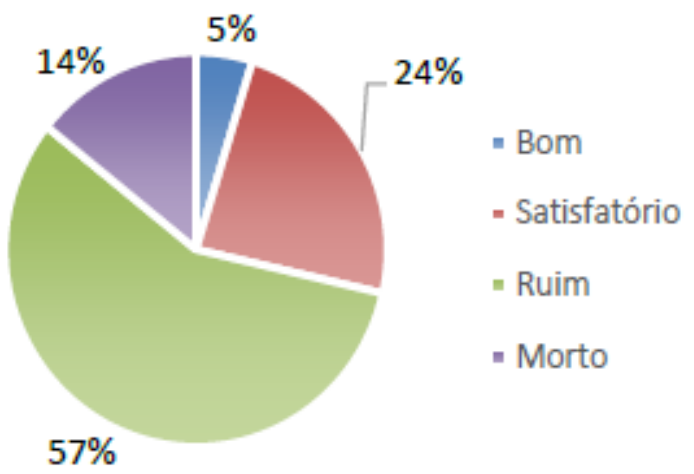

Figura 11. Estado fitossanitário dos indivíduos encontrados na Praça Capitão Valério Coelho, 2015 Figure 11. Phytosanitary condition of individuals found in Capitão Valério Coelho Square, 2015

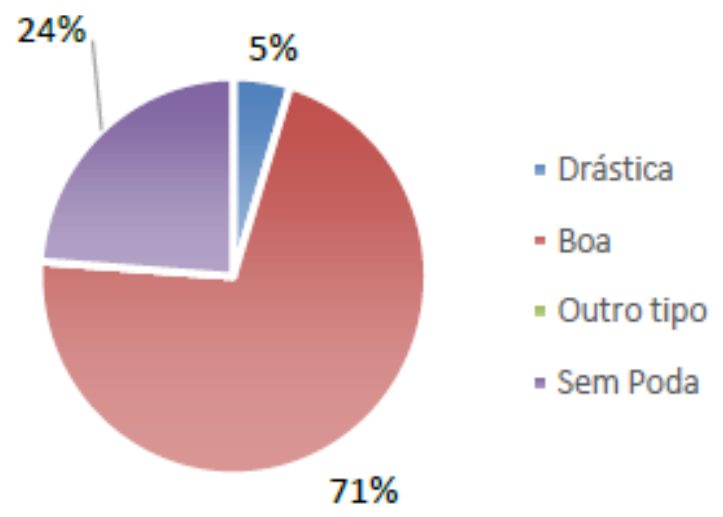

Figura 12. Condição poda dos indivíduos encontrados na Praça Capitão Valério Coelho, 2015. Figure 12. Pruning situation f individuals found in Capitão Valério Coelho Square, 2015

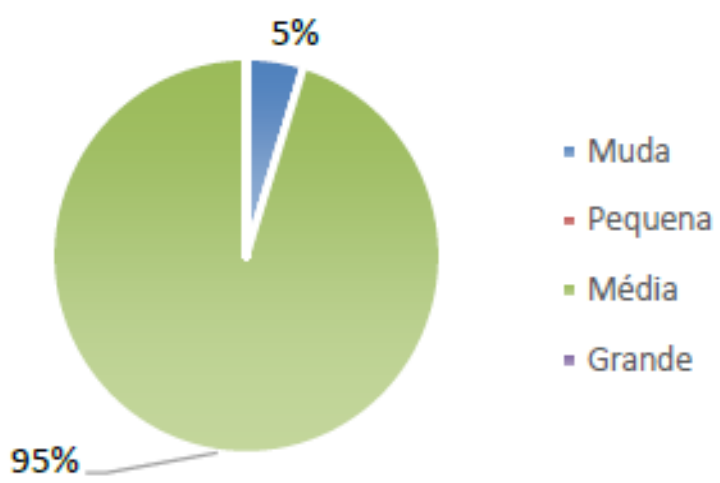

Figura 13. Porte dos indivíduos encontrados na Praça Capitão Valério Coelho, 2015

Figure 13. Size of the individuals found in Capitão Valério Coelho Square, 2015 
De forma geral, pode-se afirmar que nas quatro praças há uma presença maciça de espécies exóticas (83\%), sendo que a grande maioria é oriunda de outros continentes. As espécies mais frequentemente identificadas são: Azadirachta indica (34,21\%) e Prosopis juliflora (18,42\%). Estas duas espécies são invasoras de alto risco e podem acarretar sérios problemas para a biodiversidade local (INSTITUTO HÓRUS, 2015).

Observou-se ainda, uma tendência à propagação de Azadirachta indica, pois além de ser a espécie com maior expressividade nas praças, das 10 (dez) mudas encontradas, 7 (sete) eram da referida espécie.

Azadirachta indica provoca sérios impactos ecológicos, como por exemplo a redução de biodiversidade, pois devido sua alopatia e dominância ocasiona a supressão de outras espécies, além de reduzir a fecundidade e possuir substâncias com propriedades abortivas, o que pode acarretar na redução de algumas espécies da fauna (INSTITUTO HÓRUS, 2015).

Já Prosopis juliflora impede o desenvolvimento da vegetação nativa por dominância e competição por espaço, é grande consumidora de água, aumenta o risco de incêndios por acúmulo de biomassa, supressão da vegetação nativa e alteração no regime hídrico (NASCIMENTO et al., 2014).

O uso de espécies exóticas na arborização urbana é comum em muitas cidades, no entanto, é importante considerar que nem toda espécie exótica traz necessariamente prejuízos ambientais e/ ou sociais, pois algumas podem se manter nos locais onde foram plantadas sem se tornarem invasoras (BLUM; BORGO; SAMPAIO, 2008, p. 91).

Uma preocupação é com relação ao número elevado de espécies exóticas invasivas de alto grau que estão sendo inseridas nas praças públicas, visto que ao longo do tempo "[...] as exóticas invasoras tenderão a ocupar o espaço de espécies nativas acarretando desequilíbrios ecológicos e, em médio ou longo prazo, redução na biodiversidade regional" (BLUM; BORGO; SAMPAIO, 2008, p. 94).

Observou-se na cidade de Paulistana a inexistência de um Plano de Manejo de Praças, as árvores são plantadas aleatoriamente sem qualquer preocupação com os espaços existentes ou com os problemas que possam ocorrer futuramente, como por exemplo árvores plantadas ao lado de passeios e meios-fios, o que tem provocado a deterioração dos mesmos pelas raízes. Para Ribeiro (2009, p.225) "O plantio de árvores inadequadas à estrutura urbana gera conflitos com equipamentos urbanos como fiações elétricas, encanamentos, calhas, calçamentos, muros, postes de iluminação, etc".

Segundo Amendola (2008, p.224), “[...] a implantação de um planejamento é estritamente necessária para evitar problemas de desconforto ao homem e tudo que está ligado a ele". 
Um outro problema é a quantidade de praças públicas, principais espaços de áreas verdes da cidade de Paulistana. O município apresenta hoje 18 (dezoito) bairros, sendo que destes apenas 4 (quatro) são contemplados com praças públicas. Londe e Mendes (2014, p.268), destacam que "[...] estas áreas ao desenvolver funções ecológicas, sociais e de lazer, podem contribuir de maneira eminente, para a melhoria da qualidade ambiental e de vida da população".

Considerando a área aproximada das praças públicas $\left(9.500 \mathrm{~m}^{2}\right)$, que constituem as principais áreas verdes de Paulistana, e a população urbana (10.656 habitantes) (IBGE, 2010), obteve-se um índice de aproximadamente $0,9 \mathrm{~m}^{2} /$ habitante. Isso implica em um déficit dessas áreas no município, tendo em vista que a Organização Mundial de Saúde (OMS) recomenda que se tenha no mínimo $12 \mathrm{~m}^{2}$ de áreas verdes por habitante.

\section{CONCLUSÕES}

Foram encontrados 76 (setenta e seis) indivíduos distribuídos em 11 (onze) espécies, sendo $73 \%$ destas exóticas. As espécies mais frequentes foram Azadirachta indica (Nim) e Prosopis juliflora (Algaroba). As praças Salvador José Rodrigues, Ana Maria de Jesus e Capitão Valério Coelho, tiveram seus IDA abaixo de 1 (um), o que demonstrou que as mesmas apresentavam escassez em sua arborização.

Os indivíduos encontrados em sua maioria eram de médio porte (84\%), apresentavam estado fitossanitário satisfatório (42\%) e poda em bom estado (59\%). Quanto ao estado físico das praças, a maioria apresentavam-se com problemas estruturais (75\%).

Diante dos resultados obtidos na pesquisa, pode-se afirmar que as praças da cidade de Paulistana são ineficientes quanto a manutenção dos espécimes locais. Além de serem poucas em relação ao porte da cidade, a maioria das praças existentes apresentou sérios problemas quanto à estrutura física e grande concentração de espécies exóticas invasoras, umas das principais causas de perda da biodiversidade.

\section{REFERÊNCIAS}

AMENDOLA, L. A. Arborização urbana - a importância do planejamento. Nucleus, Ituverava, v. 5, n. 2, p. 221-242, 2008.

BLUM, C. T.; BORGO, M.; SAMPAIO, A. C. F. Espécies exóticas invasoras na arborização de vias públicas de Maringá-PR. Revista da Sociedade Brasileira de Arborização Urbana, Piracicaba, v. 3, n. 2, p. 78-97, 2008. 
EMER, A. A.; BORTOLINI, C. E.; ARRUDA, J. H.; ROCHA, K. F.; MELLO, N. A. Valorização da flora local e sua utilização na arborização das cidades. Revista Synergismus Scyentifica UTFPR, Pato Branco, v. 6, n. 1, não paginado, 2011.

FERREIRA, E. da S.; AMADOR, M. B. M. Arborização urbana: a questão das praças e calçadas no município de Lajedo-PE e a percepção da população. IX Fórum Ambiental da Alta Paulista, Tupã, v. 9, n. 4, p. 59-78, 2013.

FUNDAÇÃO CENTRO DE PRESQUISAS ECONÔMICAS E SOCIAIS DO PIAUÍ - CEPRO. Diagnóstico socioeconômico: Município Paulistana. 2013. Disponível em:<http://www. cepro.pi.gov.br/download/201105/CEPRO03_cb0cf2c36b.pdf> Acesso em: 2 out. 2015.

INSTITUTO BRASILEIRO DE GEOGRAFIA E ESTATÍTICA - IBGE. Sinopse do Censo Demográfico 2010. 2010. Disponível em: <http://www.censo2010.ibge.gov.br/sinopse/ index.php?uf=22\&dados=0 $>$. Acesso em: 2 out. 2015.

INSTITUTO BRASILEIRO DE GEOGRAFIA E ESTATÍTICA - IBGE. Informações municipais. 2015. Disponível em: <http://www.cidades.ibge.gov.br/xtras/perfil.php?lang=\&codmun=22 07801>. Acesso em: 2 out. 2015.

INSTITUTO HÓRUS. Base de dados nacional de espécies exóticas invasoras I3N Brasil, Instituto Hórus de Desenvolvimento e Conservação Ambiental. Disponível em: <http://i3n.institutohorus.org.br/www/>. Acesso em: 20 nov. 2015.

LIMA NETO, E. M. de; SOUZA, R. M. Índices de densidade e sombreamento arbóreo em áreas verdes públicas de Aracaju, Sergipe. Revista da Sociedade Brasileira de Arborização Urbana, Piracicaba, v. 4, n. 4, p. 47-62, 2009.

LONDE, P.R.; MENDES, P. C. A influência das áreas verdes na qualidade de vida urbana. Hygeia, Uberlândia, v. 10, n. 18, p. 264-272, 2014.

NASCIMENTO, C. E. de S.; TABARELLI, M.; SILVA, C. A. D. da; LEAL, I. R.; TAVARES, W. de S.; SERRÃO, J. E.; ZANUNCIO, J. C. The introduced tree Prosopis juliflora is a serious threat to native species of the Brazilian Caatinga vegetation. Science of the Total Environment, v. 481, p.108-113, 2014.

OLIVEIRA, Â. S.; SANCHES, L.; MUSIS, C. R de; NOGUEIRA, M. C.de J. A. Benefícios da arborização em praças urbanas - o caso de Cuiabá/MT. Revista Eletrônica em Gestão, Educação e Tecnologia Ambiental. Cascavel, v. 9, n. 9, p. 1900-1915, 2013.

REZENDE, T. M.; SANTOS, D.G. Avaliação quali-quantitativa da arborização das praças do bairro Jaraguá, Uberlândia - MG. Revista da Sociedade Brasileira de Arborização Urbana, Piracicaba, v. 5, n. 2, p. 139-157, 2010.

RIBEIRO, F. A. B. S. Arborização urbana em Uberlândia: percepção da população. Revista da Católica, Uberlândia, v. 1, n. 1, p. 224-237, 2009. 